\title{
Removal of emerging contaminants in wastewater by sonolysis, photocatalysis and ozonation
}

\author{
Fraiese A. ${ }^{1}$, Naddeo V. ${ }^{1,}{ }^{,}$, Uyguner-Demirel C.S. ${ }^{2}$, Prado M. ${ }^{3}$, Cesaro A. ${ }^{1}$, Zarra T. ${ }^{1}$, Liu H. ${ }^{4}$, Belgiorno V. ${ }^{1}$ and Ballesteros Jr. F. ${ }^{3}$ \\ ${ }^{1}$ Sanitary Environmental Engineering Division (SEED), Department of Civil Engineering, University of Salerno, 84084 Fisciano, Salerno, \\ via Giovanni Paolo II 132, Italy \\ ${ }^{2}$ Institute of Environmental Sciences, Bogazici University, 34342, Bebek, Istanbul, Turkey \\ ${ }^{3}$ Department of Environmental Engineering, University of the Philippines, 1101 Quezon City, Diliman, Metro Manila, Philippines \\ ${ }^{4}$ Department of Chemical \& Environmental Engineering, University of California, 9252 Riverside, CA, USA \\ Received: 13/02/2018, Accepted: 02/12/2018, Available online: 03/12/2018 \\ *to whom all correspondence should be addressed: e-mail: vnaddeo@unisa.it \\ https://doi.org/10.30955/gnj.002625
}

\section{Abstract}

Three different advanced oxidation processes (AOPs) were applied to investigate the removal of emerging contaminants (ECS) i.e. sulfamethoxazole (SMX), diclofenac (DCF) and carbamazepine (CBZ) in synthetically prepared aqueous solutions. The degradation of these substances was carried out by ozonation, sonolysis and photocatalytic oxidation, as well as by different combinations of these processes. The objectives of this work were to evaluate the removal efficiency of each method and to assess the performance variation of sonolysis in combination with other AOPs. The best performances were achieved by sonocatalysis, which resulted in the removal of the selected pharmaceuticals in the range between $37 \%$ and $47 \%$. Under similar experimental conditions, the removal of the selected ECs by single compounds by ozonation was slightly lower than the removal of respective compounds in the mixture. Moreover, pseudo first-order removal rate constants of photocatalytic mineralization were determined as $9.33 \times 10^{-2}, 4.90 \times 10^{-3}, 1.06 \times 10^{-2} \mathrm{~min}^{-1}$ for SMX, DCF and $\mathrm{CBZ}$, respectively.

Keywords: Advanced oxidation processes, catalyst, ozone, ultrasound, UV irradiation.

\section{Introduction}

Pharmaceuticals and personal care products (PPCPs) have appeared as a new class of pollutants which have been frequently detected at trace levels in wastewater effluents, rivers, lakes, seawater, groundwater and drinking water. They may accumulate in soils and sediments due to their physical and chemical properties. The occurrence of these organic emerging contaminants (ECS) in surface water and groundwater has raised an increasing attention to many researchers in the field of water engineering. With the development of advanced analytical techniques, most of these ECs at low concentrations have recently been quantified and acknowledged as potential ecological risk.
Studies on the occurrence of pharmaceuticals show that sulfamethoxazole (SMX), diclofenac (DCF) and carbamazepine (CBZ), which are among the most widely used, are present in considerable concentrations in the environment (Ternes, 1998). Diclofenac and carbamazepine are non-steroidal anti-inflammatory drugs, used against pain, fever and inflammation, and can be used without prescription. They are ubiquitously present in both municipal wastewater effluents and receiving surface waters ranging from $\mathrm{ng} / \mathrm{L}$ to $\mathrm{mg} / \mathrm{L}$ (Ternes, 1998; Heberer, 2002b). As part of the group of sulfonamides, sulfamethoxazole is a bacteriostatic antibiotic, largely used for diverse types of illness, thus causing the release of both unmetabolized and active metabolites that have a strong potential to affect organisms (Nicolle, 2002; Dantas et al., 2008). It can be found in surface waters at concentrations from 30 to $480 \mathrm{ng} / \mathrm{L}$ (Herber et al., 2008; Luo et al., 2010) and as high as $2000 \mathrm{ng} / \mathrm{L}$ in many municipal wastewater treatment plants (Andreozzi et al., 2003). The concentrations of SMX, DCF and CBZ in wastewater were reported in the range of 0.02 to $0.58 \mu \mathrm{g} \mathrm{L}^{-1}, 0.01-510 \mu \mathrm{g} \mathrm{L}^{-1}$ and $0.1-1.68 \mu \mathrm{g} \mathrm{L}^{-1}$, respectively (Klavarioti et al., 2009). Biodegradability of these compounds is generally recognized to be low and most of them cannot be removed from wastewater by conventional treatment methods (Ternes, 1998; Kümmerer et al., 2000; Heberer, 2002a).

At present, it has been widely demonstrated that advanced oxidation processes (AOPs), on the basis of a series of selective and fast oxidative reactions through the application of combinations of reactive oxidants, are effective in the removal of PPCPs (Boncz et al., 2003; Gogate and Pandit, 2004; Kunkel and Radke, 2008; Oller et al., 2011; Langenhoff et al., 2013). The efficacy of AOPs depends on the production of extremely reactive and unselective species such as hydroxyl radicals $\left({ }^{\circ} \mathrm{OH}\right)$, which degrade recalcitrant molecules into biodegradable oxidation products and eventually convert them into $\mathrm{CO}_{2}$, $\mathrm{H}_{2} \mathrm{O}$, and inorganic ions (Langenhoff et al., 2013). 
Recent studies report the removal of SMX, DCF, and CBZ by different AOPs (Doll and Frimmel, 2005; Dalrymple et al., 2007; Dantas et al., 2008; Beltrán et al., 2009; Beltrán et al., 2012; Carbonaro et al., 2013). The applicability of ozonation and advanced oxidation technologies to remove endocrine disrupting chemicals, pharmaceuticals and personal care products in water effluents was reviewed in detail by Esplugas et al. (2007). A very recent critical review by Hübner et al. (2015) also reports on the ozonation of several ECs and evaluates the persistence of transformation products.

The objective of this study was to investigate the removal of DCF, SMX, CBZ by three AOPs, specifically, sonolysis, ozonation and $\mathrm{TiO}_{2}$ photocatalysis. Combinations of these AOPs were also investigated to compare the efficiencies of combined processes on the basis of the removal of target organic contaminants.

\section{Materials and methods}

\subsection{Chemicals}

In this study, diclofenac (DCF, $\mathrm{C}_{14} \mathrm{H}_{10} \mathrm{Cl}_{2} \mathrm{NNaO}_{2}$, molecular weight: $318.13 \mathrm{~g})$, sulfamethoxazole $\left(\mathrm{SMX}, \mathrm{C}_{10} \mathrm{H}_{11} \mathrm{~N}_{3} \mathrm{O}_{3} \mathrm{~S}\right.$, molecular weight: $253.28 \mathrm{~g}$ ) and carbamazepine (CBZ, $\mathrm{C}_{15} \mathrm{H}_{12} \mathrm{~N}_{20}$, molecular weight: $236.27 \mathrm{~g}$ ) were used as model compounds for pharmaceuticals. They were spiked into distilled water to prepare working solutions with concentrations ranging from 4 to $10 \mathrm{mg} \mathrm{L}^{-1}$ to be used for experiments. The concentrations detected in real wastewater of this type of pharmaceuticals, as previously mentioned, are normally in range of 0.02 to $0.58 \mu \mathrm{g} \mathrm{L}^{-1}$, 0.01-510 $\mu \mathrm{g} \mathrm{L}^{-1}$ and 0.1-1.68 $\mu \mathrm{g} \mathrm{L}^{-1}$, for SMX, DCF and CBZ respectively. As this work was carried out on synthetic aqueous solutions, also based on previous studies from the authors (Naddeo et al., 2015), higher concentrations were chosen for analytical requirements, in order to assess the process efficiency within a measurable time scale as well as an accurate analytical determination with the applied methods at bench scale. Moreover, as the removal of such high concentrations by sonolysis demonstrated zero-order kinetics in previous studies (Naddeo et al., 2009b), the prediction of treatment efficiency at lower concentrations in wastewater is reasonable.

\subsection{Experimental set-up}

Ozonation was conducted with a UV system (model Ozone - Procom srl), which produced ozone by UV splitting of the oxygen molecules in the provided ambient air. The air flow was constant over time and the ozone working rate was determined by Standard Method 2350E 106 (Ozone Demand/Requirement-Semi-Batch Method). The ozone dose was set at $3.3 \mathrm{~g} \mathrm{~h}^{-1}$ for the individual process (Naddeo et al., 2015) and treatment duration was controlled within $40 \mathrm{~min}$. Photocatalytic oxidation experiments were performed using $0.5 \mathrm{~g} \mathrm{~L}^{-1}$ of Degussa P$25 \mathrm{TiO}_{2}$ which was irradiated from the top by a 125-W BLF lamp. The light intensity measured by potassium ferrioxalate actinometry was $4.7 \times 10^{-7}$ Einstein $\bullet \mathrm{s}^{-1}$. The optimal $\mathrm{TiO}_{2}$ dose was determined based on previous studies (Uyguner et al., 2007). The $\mathrm{TiO}_{2}$ suspension was continuously stirred by a magnetic stirrer. Sonolysis experiments were conducted with a Sonics Vibracell TM VCX-750 (Sonics Material Inc., USA) ultrasound generator operating at a fixed frequency of $20 \mathrm{kHz}$ and equipped with a titanium horn with a tip of $1.3 \mathrm{~cm}$ diameter. The applied power was set constant at $60 \%$ of amplitude. The tests were carried out at different sonication times (10 and $30 \mathrm{~min}$ ) with an ultrasonic density of $370 \mathrm{~W} \mathrm{~L}^{-1}$. A Thermocouple immersed in solution was employed to measure bulk temperature of the sample that was kept constant by the use of a water bath. The same devices were used to study the combined ozone/sonolysis process and sonolysis/ $\mathrm{TiO}_{2}$ photocatalysis (i.e., sonocatalysis). Operating conditions are given in Table 1.

Table 1. Investigated operating conditions for combined processes

\begin{tabular}{|c|c|c|c|c|}
\hline & $\begin{array}{c}\text { Combined } \\
\text { process }\end{array}$ & $\begin{array}{l}\text { Sonolysis } \\
\text { amplitude }\end{array}$ & $\begin{array}{l}\text { Treatment } \\
\text { time }\end{array}$ & \\
\hline \multirow{3}{*}{$\begin{array}{c}\mathrm{O}_{3} \\
\text { Dose }\end{array}$} & $1.3 \mathrm{~g} \mathrm{~h}^{-1}$ & \multirow{3}{*}{$\mathrm{O}_{3}+\mathrm{US}$} & \multirow{3}{*}{$\begin{array}{l}30 \% \\
60 \%\end{array}$} & \multirow{3}{*}{$\begin{array}{l}20 \mathrm{~min} \\
40 \mathrm{~min}\end{array}$} \\
\hline & $2.4 \mathrm{~g} \mathrm{~h}^{-1}$ & & & \\
\hline & $3.3 \mathrm{~g} \mathrm{~h}^{-1}$ & & & \\
\hline $\begin{array}{c}\mathrm{TiO}_{2} \\
\text { Dose }\end{array}$ & $0.5 \mathrm{mg} \mathrm{L}^{-1}$ & $\mathrm{TiO}_{2}+\mathrm{US}$ & $60 \%$ & $\begin{array}{l}10 \mathrm{~min} \\
30 \mathrm{~min}\end{array}$ \\
\hline
\end{tabular}

The combined ozone/sonolysis tests were performed without $\mathrm{pH}$ adjustment of the synthetic solutions. The natural $\mathrm{pH}$ of the samples was between 4.5 and 5.0, which decreased to a $\mathrm{pH}$ in the range of 3.5 and 4.0 after the application of ultrasound. All the tests were performed in triplicate, using $200 \mathrm{~mL}$ of sample at different concentrations.

\subsection{Analytical methods}

The quantification of the selected ECs was conducted with UV-vis spectrophotometry (Perkin Elmer Lambda 12). Concentrations of DCF, SMX and CBZ were analyzed by 4000 Q Trap LC-MS/MS System (Applied Biosystems, Foster City, USA) with electrospray ionization (ESI) - positive and negative ionization modes. In the LC MS/MS, carbamazepine and diclofenac were analyzed in ESI-positive mode using a mobile phase composed of $A$ : $0.1 \%$ formic acid in water and $\mathrm{B}$ : acetonitrile-water (1:1 v/v) solution. An Inertsil ODS-3 C18 column was used for the separation step (Secondes et al., 2014). Temperature all throughout the process and $\mathrm{pH}$ at certain points were monitored by $\mathrm{pH} 211$ microprocessor $\mathrm{pH}$ meter (Hann Instruments, USA). Shimadzu VWP-TOC Total Organic Carbon analyzer was used to determine the dissolved organic carbon contents (DOC) of the samples. Moreover, the quantification of anions formed during photocatalytic oxidation was carried out using Dionex ICS-3000 Ion Chromatography. 


\section{Results and discussion}

\subsection{Ozonation}

The performance of ozonation on the degradation of pharmaceuticals was evaluated based on the removal efficiency in the presence of a single compound as well as in a mixture of three compounds (Naddeo et al., 2015). After 40 minutes of reaction, ozonation at a dosage of $10 \mathrm{mg} \mathrm{O}_{3} \mathrm{~L}^{-1}$ resulted in approximately $51 \%, 73 \%$, and $59 \%$ removal of SMX, DCF and CBZ, respectively. These results are consistent with those reported by Naddeo et al. (2015). The highest removal rate was observed for DCF, followed by CBZ. This evidence suggests that a lower ozone dosage is needed to remove DCF and CBZ than SMX. This trend is likely associated with the distinct molecular structure of the three compounds. The aromatic amino groups in DCF and SMX are likely exposed to the ozone attack (Dantas et al., 2008), but different ring positions are responsible for the highest reactivity of DCF upon SMX. In the case of CBZ, ozone tends react rapidly with the double bonds in yielding several ozonation products containing quinazoline-based functional groups (McDowell et al., 2005). The high reactivity of CBZ with ozone has a second order rate constant of $3 \times 105 \mathrm{M}^{-1} \mathrm{~s}^{-1}$ (Huber et al., 2003). The experimental activity performed on the mixture of pharmaceuticals showed that, despite the simultaneous presence of all target compounds, a significant reduction of DCF was obtained after 40 minutes, as already found in previous studies (Naddeo et al., 2015). Under similar experimental conditions, the removal of single compounds by ozonation was slightly higher than the removal of respective compounds in the mixture. This was due to the competitive kinetics of three compounds reacting with ozone. In addition, the ozonation reaction can proceed via both direct and indirect pathways. In the direct ozonation, the ozone molecule reacts with the target compound, while in the indirect ozonation, the reaction take place in the presence of hydroxyl radicals, which are the products of the dissociation of ozone in aqueous solution at high $\mathrm{pH}$ values (Rodríguez et al., 2008). The direct reactions between ozone and organic compounds in aqueous solutions are essentially limited to unsaturated and aromatic compounds, and the reactivity is governed by the dipolar structure of the ozone molecule. It is very well known that the degradation by ozone can lead to the complete removal of the selected emerging compounds under optimized conditions, but an accumulation of ozonation by-products (e.g., phenolic intermediates and carboxylic acids) in solution can also be observed (Dantas et al., 2008; Hübner et al., 2015).

\subsection{Photocatalytic oxidation}

Photocatalytic oxidation of pharmaceuticals in the presence of a single compound as well as in a mixture of three was investigated. UV spectra of the photocatalytic degradation profile of $10 \mathrm{mg} \mathrm{L}^{-1} \mathrm{SMX}, \mathrm{CBZ}$ and DCF showed a higher removal efficiency with respect to increasing irradiation periods. After 60 mins of irradiation almost complete removal of the broad peak around
260-300 nm was observed. Oxidation leads to the formation of organic intermediate compounds. It would be possible to detect the target compounds by UV absorbance measurement only in the early stage, since these are in higher concentration than the oxidation intermediates. Moreover, DOC analysis could be used to verify the presence of all organic compounds or their mineralization (Rizzo et al., 2009). Under experimental conditions where photocatalytic removal of DCF (10 $\mathrm{mg} \mathrm{L}^{-1}$ ) was studied, $23 \%$ and $53 \%$ removal of DCF was observed after 30 and 60 mins of UV irradiation, respectively (Figure $1(\mathrm{a})$ ). The same catalyst was studied by Achilleos et al. (2010) for the removal of $10 \mathrm{mg} \mathrm{L}^{-1} \mathrm{DCF}$ : $250 \mathrm{mg} \mathrm{L}^{-1}$ of Degussa P25 resulted in $61 \%$ conversion of the target compound after 60 minutes. In another study, $50 \mathrm{mg} \mathrm{L}^{-1}$ of DCF was almost totally removed using $200 \mathrm{mg}$ $\mathrm{L}^{-1}$ of $\mathrm{TiO}_{2}$ loading under extended irradiation (PérezEstrada et al., 2005). Such outcomes suggest the importance of the irradiation conditions, not only in terms of treatment time but also with reference to the experimental set up used for the experiments. The same experimental conditions resulted in higher removal of SMX (Figure $1(\mathrm{~b})$ ), which reached $55 \%$ and $82 \%$ after 30 and 60 minutes treatment, respectively. Photocatalytic oxidation studies by Beltrán et al. (2008) with SMX in the range of 30 to $80 \mathrm{mg} \mathrm{L}^{-1}$ were carried out using $1.5 \mathrm{~g} \mathrm{~L}^{-1}$ $\mathrm{TiO}_{2}$ where approximately $100 \%$ removal of target compound was achieved in less than 20 min (Beltrán et al., 2008). Using different reaction conditions and $\mathrm{TiO}_{2}$ loading, various removals were reported in literature (Abellán et al., 2007; Nasuhoglu et al., 2011; Xekoukoulotakis et al., 2011). The removal yields obtained for CBZ (Figure 1(c)) were comparable to those observed for SMX. The photocatalytic removal of the mixture of pharmaceuticals containing $10 \mathrm{mg} \mathrm{L}^{-1}$ of DCF, SMX and CBZ revealed $20 \%$ of DOC removal after $60 \mathrm{~min}$ (Figure 1(d)). Even from the initial periods of photocatalysis, the concentration of both chloride and sulfate gradually increased with irradiation time. On the other hand, the nitrate level increased steadily from 0 to 60 minutes.

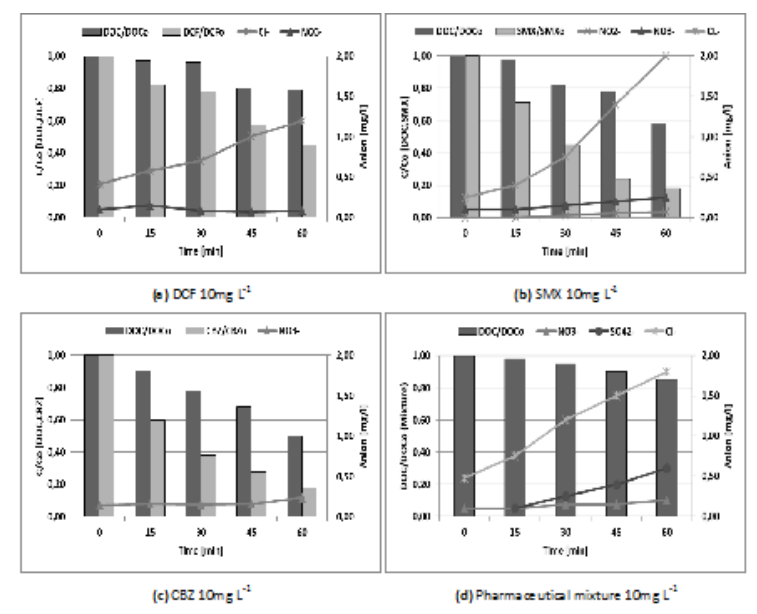

Figure 1. DOC removal, anion and pharmaceutical concentrations during photocatalytic oxidation 
As for the removal rates, the photocatalytic degradation of pharmaceuticals generally followed pseudo first-order kinetics. The photocatalytic removal rate constants $(k)$ of each compound were evaluated and presented in Table 2. As pointed out in previous studies (Jelic et al., 2013; Rao et al., 2013; Wang et al., 2018), the photocatalytic oxidation of carbamazepine also revealed pseudo firstorder rate constants that confirmed a beneficial effect on the process kinetics due to the increased number of $\mathrm{TiO}_{2}$ active sites. It should be highlighted that for higher concentrations these effects tended to stabilise. This behavior is a function of the reactor and the used $\mathrm{TiO}_{2}$ type and loading (Doll and Frimmel, 2004).

Table 2. Pseudo first-order removal rate constants for the photocatalytic degradation of SMX, DCF and CBZ in terms of both DOC and concentration of Emerging Contaminant (EC) (k: rate constant, $R^{2}>0.90$ )

\begin{tabular}{ccc}
\hline & KDOC $\left[\mathrm{min}^{-1}\right]$ & KEC $\left[\mathrm{min}^{-1}\right]$ \\
\hline $10 \mathrm{mg} \mathrm{L}^{-1} \mathrm{SMX}$ & $9.33 \times 10^{-3}$ & $2.59 \times 10^{-2}$ \\
\hline $10 \mathrm{mg} \mathrm{L}^{-1} \mathrm{DCF}$ & $4.90 \times 10^{-3}$ & $1.28 \times 10^{-2}$ \\
\hline $10 \mathrm{mg} \mathrm{L}^{-1} \mathrm{CBZ}$ & $1.06 \times 10^{-2}$ & $2.70 \times 10^{-2}$ \\
\hline Mixture & $3.60 \times 10^{-3}$ & --- \\
\hline
\end{tabular}

DOC removal rate constants of ECs followed the order of $\mathrm{CBZ}>\mathrm{SMX}>\mathrm{DCF}>$ mixture (Table 2). In general, mineralization rate was slower than that corresponding to the target compound removal. This is due to the presence of oxidation products in the medium. Considering that DOC embraces the entire organic load of the samples, not only the degradation of the target EC, but also the global degradation of all compounds in the solution is measured. UV254 parameter was chosen to represent aromaticity removal of the residual substrate as well as the reaction intermediates. In a recent study by Jelic et al. (2013), pseudo first-order rate constants corresponding to photocatalytic degradation of CBZ (10 mg $\left.\mathrm{L}^{-1}\right)$ was reported as $1.75 \times 10^{-2} \mathrm{~min}^{-1}$. Upon UV-A irradiation (at $25 \mathrm{~W} \mathrm{~L}^{-1}$ intensity) of $\mathrm{CBZ}$ and $\mathrm{TiO}_{2}$ solution in pure water, a DOC reduction of $45 \%$ and a CBZ substrate conversion of $75 \%$ were observed after 120 mins. In another study conducted by Miranda-Garcia et al. (2011) photocatalytic degradation of 15 ECs at low concentrations was investigated in simulated and real municipal wastewater treatment plant using $\mathrm{TiO}_{2}$ immobilized on glass spheres where $85 \%$ of the compounds was degraded within 120 min of illumination time, depending on the water matrix. The results showed that using a $5 \mathrm{mg} \mathrm{L}^{-1}$ suspension of Degussa P25 $\mathrm{TiO}_{2}$ led to a decrease in the removal of the contaminants except for ofloxacin, hydroxybiphenyl, diclofenac, progesterone and triclosan which were degraded in less than $120 \mathrm{~min}$. On the other hand, photocatalytic mineralization rate of an urban wastewater effluent contaminated with a mixture of pharmaceutical compounds composed of amoxicillin (10 $\left.\mathrm{mg} \mathrm{L}^{-1}\right)$, carbamazepine $\left(5 \mathrm{mg} \mathrm{L}^{-1}\right)$ and diclofenac (2.5 $\mathrm{mg} \mathrm{L}^{-1}$ ) was found to be really slow $\left(t_{1 / 2}=86.6 \mathrm{~min}\right)$ when compared to those of the same pharmaceuticals spiked in distilled water $\left(\mathrm{t}_{1 / 2}=46.5 \mathrm{~min}\right)$ (Rizzo et al., 2009).

Photocatalysis is a degrading process and, hence, several intermediates of varying reactivity are likely to be formed prior to mineralization; some of them are expected to be quite recalcitrant to further decomposition, suggesting that the complete mineralization rate should be slower than the degradation rate of ECs. Photocatalytic mineralization rate constant of single compounds as determined by DOC removal was higher than the removal rate constant of the mixture.

\subsection{Sonolysis-enhanced advanced oxidation processes}

\subsubsection{Sonolysis}

Preliminary studies were performed with model compounds to optimize sonolysis operating conditions. The results showing the removal of each compound after sonolysis application for 10 and $30 \mathrm{~min}$ are shown in Figure 2. Using $4 \mathrm{mg} \mathrm{L}^{-1}$ mixture (Figure 2(a)), application of sonolysis for $10 \mathrm{~min}$ led to $12 \%, 3 \%$ and $13 \%$ removal of SMX, DCF and CBZ, respectively. Extending the application time to $30 \mathrm{~min}$ resulted in an enhanced removal of $27 \%$, $26 \%$ and $29 \%$ of the respective ECs. With the increase in mixture concentration to $10 \mathrm{mg} \mathrm{L}^{-1}$ (Figure 2(b)), no significant change was observed after 10 min application of ultrasound. However, after $30 \mathrm{~min}, 13 \%, 9 \%$ and $2 \%$ removal in concentrations of SMX, DCF and CBZ were attained. Recent research on the degradation of SMX, DCF and $\mathrm{CBZ}$ as single compounds revealed no significant change in the removal rate of compound and DOC, although conversion of the compound to more readily biodegradable forms could be achieved (Naddeo et al., 2010).

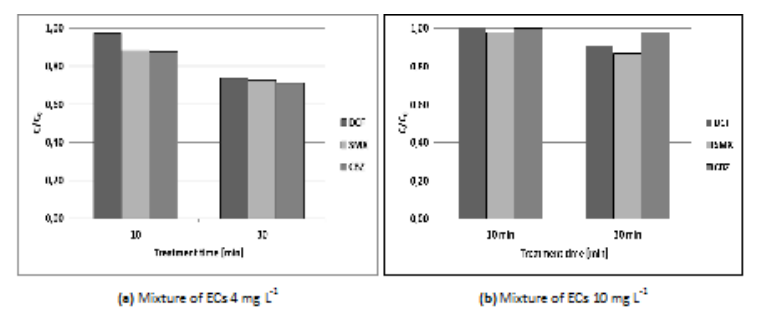

Figure 2. Treatment process for the removal of mixture of ECs (60\% amplitude)

Different results were reported in literature regarding the application of sonolysis for the removal of SMX, DCF and CBZ. However, most of the studies were based on sonolysis application for the removal of single compounds in aqueous solutions. The simultaneous presence of different pharmaceuticals could affect the ultrasonic degradation of respective compounds in single solutions that was assumed to occur by the hydroxyl radicals present in the bubble-liquid interface due to the hydrophobic and low volatile properties of the target compounds (Méndez-Arriaga et al., 2008; Liwei Hou, 2013). 


\subsubsection{Combined ozonation and sonolysis}

Tables 3 and 4 present the results of the combined ozonation/sonolysis process on the selected pharmaceuticals both as single compounds and in mixture.

Table 3. Removal \% of single compounds of SMX, DCF and CBZ (10 mg L-1 each) by combined ozonation and sonolysis

\begin{tabular}{|c|c|c|c|c|c|c|c|}
\hline \multicolumn{2}{|c|}{ Treatment } & \multicolumn{2}{|c|}{ SMX [\% removal] } & \multicolumn{2}{|c|}{ DCF [\% removal] } & \multicolumn{2}{|c|}{ CBZ [\% removal] } \\
\hline Ozone dose $[\mathrm{g} / \mathrm{h}]$ & $\begin{array}{c}\text { Ultrasound } \\
\text { amplitude [\%] }\end{array}$ & $20 \mathrm{~min}$ & $40 \mathrm{~min}$ & $20 \mathrm{~min}$ & $40 \mathrm{~min}$ & $20 \mathrm{~min}$ & $40 \mathrm{~min}$ \\
\hline 1.3 & 30 & 30 & 50 & 54 & 75 & 28 & 44 \\
\hline 1.3 & 60 & 42 & 51 & 62 & 86 & 32 & 41 \\
\hline 2.4 & 30 & 38 & 55 & 63 & 89 & 41 & 49 \\
\hline 2.4 & 60 & 44 & 52 & 72 & 91 & 41 & 46 \\
\hline 3.3 & 30 & 26 & 34 & 66 & 90 & 47 & 54 \\
\hline 3.3 & 60 & 54 & 61 & 80 & 94 & 50 & 52 \\
\hline
\end{tabular}

Table 4. Removal \% of SMX, DCF and CBZ (10 $\mathrm{mg} \mathrm{L}^{-1}$ each) mixture by combined ozonation and sonolysis

\begin{tabular}{|c|c|c|c|c|c|c|c|}
\hline \multicolumn{2}{|c|}{ Treatment } & \multicolumn{2}{|c|}{ SMX [\% removal] } & \multicolumn{2}{|c|}{ DCF [\% removal] } & \multicolumn{2}{|c|}{ CBZ [\% removal] } \\
\hline Ozone dose $\left[\mathrm{g} \mathrm{h}^{-1}\right]$ & $\begin{array}{c}\text { Ultrasound } \\
\text { amplitude [\%] }\end{array}$ & $20 \mathrm{~min}$ & $40 \mathrm{~min}$ & $20 \mathrm{~min}$ & $40 \mathrm{~min}$ & $20 \mathrm{~min}$ & $40 \mathrm{~min}$ \\
\hline 1.3 & 30 & 22 & 45 & 37 & 62 & 21 & 35 \\
\hline 1.3 & 60 & 36 & 45 & 54 & 85 & 29 & 37 \\
\hline 2.4 & 30 & 33 & 50 & 54 & 84 & 34 & 43 \\
\hline 2.4 & 60 & 41 & 46 & 64 & 88 & 35 & 42 \\
\hline 3.3 & 30 & 21 & 30 & 59 & 85 & 40 & 46 \\
\hline 3.3 & 60 & 51 & 55 & 73 & 90 & 44 & 49 \\
\hline
\end{tabular}

In both cases, the combined effect of ozonation and sonolysis synergetically improved the removal efficiency of the studied compounds. This is due to the fact that the ultrasonic waves homogenized the sample and improved the solubility of ozone by high energy and vibration, as extensively proved in other studies (Kidak and Dogan, 2012).

For the three pharmaceuticals, respective removal of the target compound in the mixture also relevantly increased with increasing ozone dose as well as time. In general, the percentage removal of each emerging compound in the mixture is lower than the removal percentage of the compound in a single-compound matrix. The results carried out at $60 \%$ amplitude confirmed those reported by Naddeo et al. (2015).

Figure 3 compares pharmaceutical removal after the application of the combined ozonation/sonolysis process both in single solution and in mixture.

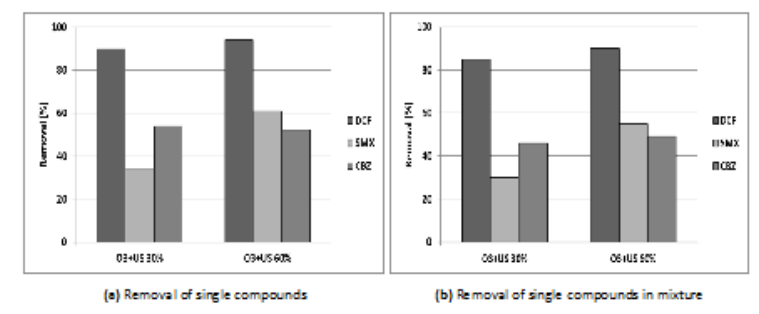

Figure 3. Comparison of the percent removals of single compounds and mixture of SMX, DCF, CBZ by combined ozonation $\left(\mathrm{O}_{3}\right)$ and sonolysis (US) at 30 and $60 \%$ of amplitude (ozone flow $3,3 \mathrm{~g} \mathrm{~h}^{-1}$, time $40 \mathrm{~min}$ )
Higher removals were attained using the combined process operating under high ultrasonic amplitude. As the amplitude increased from $30 \%$ to $60 \%$, the removal of SMX and DCF improved up to $61 \%$ and $94 \%$, respectively. The observed synergy was mainly due to an enhanced rate of $\mathrm{O}_{3}$ diffusion to the bulk solution and into the cavity bubbles, which upon collapse lead to thermal decomposition of the contents for an additional and major route of ${ }^{\bullet} \mathrm{OH}$ production.

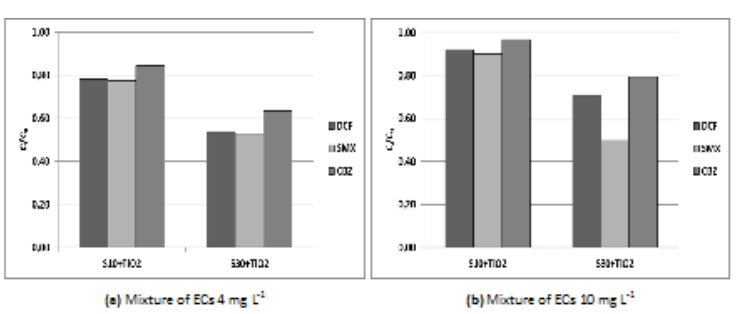

Figure 4. Treatment process for the removal mixture of ECS $\left(\mathrm{S} 10+\mathrm{TiO}_{2}: 10\right.$ min sonolysis in the presence of $\mathrm{TiO}_{2}, \mathrm{~S}_{3} 0+\mathrm{TiO}_{2}$ : $30 \mathrm{~min}$ sonolysis in the presence of $\mathrm{TiO}_{2}$ )

The increase in efficiency in hybrid processes is related to factors such as enhanced mass transfer rates of gases and solutes, enlarged surface areas of solids, excess bubble nuclei and excess ${ }^{\circ} \mathrm{OH}$ formation. Hybrid processes of ozone and sonolysis were shown to be effective, as they provide complete degradation and appreciable mineralization of the compound (Naddeo et al., 2009a). It was reported that approximately 5\%, 30\% and $50 \%$ mineralization was achieved by $100 \mathrm{~W} \mathrm{~L}^{-1}, 200 \mathrm{~W}$ $\mathrm{L}^{-1}$ and $400 \mathrm{~W} \mathrm{~L} \mathrm{~L}^{-1}$ power densities within $60 \mathrm{~min}$, 
at an initial concentration of $40 \mathrm{mg} \mathrm{L}^{-1}$ of DCF (Naddeo et al., 2009a). Similar results were reported by Hou et al. (2013) and Guo et al. (2015) for the removal of SMX under various operating conditions.

\subsubsection{Sonocatalysis}

To study the effect of $\mathrm{TiO}_{2}$ on the sonolytic degradation of the selected pharmaceuticals, sonolysis experiments were performed in the presence of $0.5 \mathrm{mg} \mathrm{mL}^{-1} \mathrm{TiO}_{2}$. At initial concentration of $4 \mathrm{mg} \mathrm{L}^{-1}$ and 10 minutes sonocatalysis of the EC mixture revealed $23 \%, 22 \%$ and $15 \%$ removal of SMX, DCF and CBZ respectively. Increasing sonication time to $30 \mathrm{~min}$ resulted in $47 \%, 46 \%$ and $37 \%$ removal in respective pharmaceuticals, as shown in Figure 4.

This evidence highlights a synergistic effect in the degradation of the studied compounds by the combined effect of catalyst and sonolysis, which was attributed to the additional cavitation activity (Méndez-Arriaga et al., 2008). Ultrasound has a mechanical effect that may lead to the fragmentation of catalyst and the consequent increase of the surface area and active sites. Another possible effect is the increase of the mass transfer between the reactants and the catalyst (Pandit et al., 2001). In contrast to our findings, no significant difference on the removal efficiency of SMX $\left(50 \mathrm{mg} \mathrm{L}^{-1}\right)$ was reported by Hou et al. (2013) in the presence of ultrasound (85.7 W L $\mathrm{W}^{-1}$ ) and $\mathrm{Fe}_{3} \mathrm{O}_{4}$ catalyst $\left(0.3 \mathrm{~g} \mathrm{~L}^{-1}\right)$. On the other hand, in parallel with the decrease in concentration, for both mixtures ( 4 and $10 \mathrm{mg} \mathrm{L}^{-1}$ ), UV-vis spectra specifically in 250-300 $\mathrm{nm}$ region also revealed a slight decrease in absorbance intensity after the application of sonolysis and sonocatalysis (Figure 5). Although sonolysis and sonocatalysis resulted in around $10 \%$ and $40 \%$ removal in the concentration of ECS, smooth decrease of the UV-Vis spectra accompanied by any significant change in DOC values (data not shown) indicated inefficient mineralization and formation of new products by the degradation of SMX, DCF and CBZ.

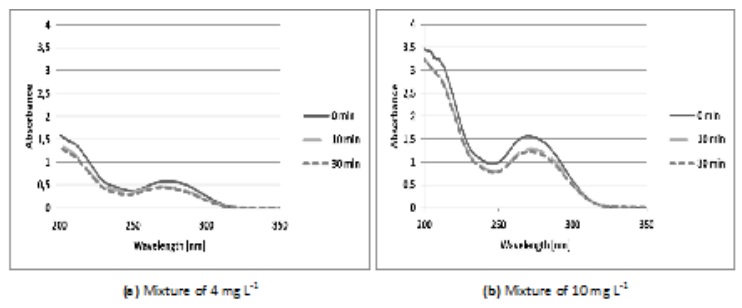

Figure 5. UV-vis spectra of mixture during sonocatalysis: sonication time 10 and $30 \mathrm{~min}$

\section{Conclusion}

AOPs are effective in the removal of the most widely used pharmaceuticals, i.e., SMX, DCF and CBZ, which have been recognized as ECs. Different results were obtainedas a consequence of different operating conditions. The simultaneous presence of selected compounds in mixture led to a slight reduction in the removal efficiency provided by 40 minutes of ozonation. The process yields were found to be enhanced by the combined application of ozone and ultrasound. The combined ozonation and sonolysis process resulted in DCF elimination in the range of 90 to $94 \%$ according to the applied ultrasonic amplitude. The photocatalytic removal of the mixture of pharmaceuticals containing $10 \mathrm{mg} \mathrm{L}^{-1}$ of DCF, SMX and CBZ revealed $20 \%$ of $\mathrm{DOC}$ removal after $60 \mathrm{~min}$. Pseudo first order removal rate constants of photocatalytic mineralization were determined as $9.33 \times 10^{-2}, 4.90 \times 10^{-3}, 1.06 \times 10^{-2} \mathrm{~min}^{-1}$ for SMX, DCF and $\mathrm{CBZ}$, respectively. On the other hand, sonocatalysis results showed that, despite the reduction in target compound concentrations, no significant variation occurred as DOC, indicating inefficient mineralization and the formation of other products from the degradation of ECs. The formation of intermediates was confirmed as one of the most important issue related to the application of AOPs. Further studies should be addressed to the characterization of the products from the treatment of different pharmaceuticals, either as single compounds or in mixture, in order to extrapolate research findings to the whole class of pharmaceuticals and promote the wider application of AOPs.

\section{Acknowledgments}

Research activities were partially funded by the FARB project at the University of Salerno (ORSA113283), the Bilateral Research Project between Italy and Turkey (TUBITAK project No.111Y303), and the U.S. National Science Foundation (CHE-1611306). The authors wish to thank the laboratory technician Paolo Napodano and Dr. Anna Farina for their valuable help in the analytical work and Dr. Dario Galdi for the cooperation.

\section{References}

Abellán M.N., Bayarri B., Giménez J. and Costa J. (2007), Photocatalytic degradation of sulfamethoxazole in aqueous suspension of $\mathrm{TiO}_{2}$, Applied Catalysis B: Environmental, 74, 233-241.

Achilleos A., Hapeshi E., Xekoukoulotakis N.P., Mantzavinos D. and Fatta-Kassinos D. (2010), Factors affecting diclofenac decomposition in water by $\mathrm{UV}-\mathrm{A} / \mathrm{TiO}_{2}$ photocatalysis, Chemical Engineering Journal, 161, 53-59.

Andreozzi R., Caprio V., Marotta R. and Radovnikovic A. (2003), Ozonation and $\mathrm{H}_{2} \mathrm{O}_{2} / \mathrm{UV}$ treatment of clofibric acid in water: a kinetic investigation, Journal of Hazardous Materials, 103, 233-246.

Beltrán F.J., Aguinaco A. and García-Araya J.F. (2009), Mechanism and kinetics of sulfamethoxazole photocatalytic ozonation in water, Water Research, 43, 1359-1369.

Beltrán F.J., Aguinaco A., García-Araya J.F. and Oropesa A. (2008), Ozone and photocatalytic processes to remove the antibiotic sulfamethoxazole from water, Water Research, 42, 3799-3808.

Beltrán F.J., Aguinaco A., Rey A. and García-Araya J.F. (2012), Kinetic studies on black light photocatalytic ozonation of diclofenac and sulfamethoxazole in water, Industrial \& Engineering Chemistry Research, 51, 4533-4544.

Boncz M., Bruning H. and Rulkens W. (2003), Innovative reactor technology for selective oxidation of toxic organic pollutants in wastewater by ozone, Water Science \& Technology, 47, $17-24$. 
Carbonaro S., Sugihara M.N. and Strathmann T.J. (2013), Continuous-flow photocatalytic treatment of pharmaceutical micropollutants: activity, inhibition, and deactivation of $\mathrm{TiO}_{2}$ photocatalysts in wastewater effluent, Applied Catalysis B: Environmental, 129, 1-12.

Dalrymple O.K., Yeh D.H. and Trotz M.A. (2007), Removing pharmaceuticals and endocrine-disrupting compounds from wastewater by photocatalysis, Journal of Chemical Technology and Biotechnology, 82, 121-134.

Dantas R.F., Contreras S., Sans C. and Esplugas S. (2008), Sulfamethoxazole abatement by means of ozonation, Journal of Hazardous Materials, 150, 790-794.

Doll T.E. and Frimmel F.H. (2004), Kinetic study of photocatalytic degradation of carbamazepine, clofibric acid, iomeprol and iopromide assisted by different $\mathrm{TiO}_{2}$ materialsdetermination of intermediates and reaction pathways, Water Research, 38, 955-964.

Doll T.E. and Frimmel F.H. (2005), Removal of selected persistent organic pollutants by heterogeneous photocatalysis in water, Catalysis Today, 101, 195-202.

Esplugas S., Bila D.M. Krause L.G.T. and Dezotti M. (2007), Ozonation and advanced oxidation technologies to remove endocrine disrupting chemicals (EDCs) and pharmaceuticals and personal care products (PPCPs) in water effluents, Journal of Hazardous Materials, 149, 631-642.

Gogate P.R. and Pandit A.B. (2004), A review of imperative technologies for wastewater treatment II: hybrid methods, Advances in Environmental Research, 8, 553-597.

Guo W.Q., Yin R.L. Zhou X.J., Du J.S., Cao H.O., Yang S.S. and Ren N.Q. (2015), Sulfamethoxazole degradation by ultrasound/ozone oxidation process in water: kinetics, mechanisms, and pathways, Ultrasonics Sonochemistry, 22, 182-187.

Heberer T. (2002a), Occurrence, fate, and removal of pharmaceutical residues in the aquatic environment: a review of recent research data, Toxicology Letters, 131, 5-17.

Heberer T. (2002b), Tracking persistent pharmaceutical residues from municipal sewage to drinking water, Journal of Hydrology, 266, 175-189.

Heberer T., Massmann G., Fanck B., Taute T. and Dünnbier U. (2008), Behaviour and redox sensitivity of antimicrobial residues during bank filtration, Chemosphere, 73, 451-460.

Huber M.M., Canonica S., Park G.Y. and von Gunten U. (2003), Oxidation of pharmaceuticals during ozonation and advanced oxidation processes, Environmental Science \& Technology, 37, 1016-1024.

Hübner U., von Gunten U., Jekel M. (2015), Evaluation of the persistence of transformation products from ozonation of trace organic compounds - A critical review, Water Research, 68, 150-170.

Hou L.H.Z. (2013), Removal of sulfamethoxazole from aqueous solution by sono-ozonation in the presence of a magnetic catalyst, Separation and Purification Technology, 117, 46-52.

Jelic A., Michael I., Achilleos A., Hapeshi E., Lambropoulou D., Perez S., Petrovic M., Fatta-Kassinos D. and Barcelo D. (2013), Transformation products and reaction pathways of carbamazepine during photocatalytic and sonophotocatalytic treatment, Journal of Hazardous Materials, 263, 177-186.

Kidak R. and Dogan S. (2012), Degradation of Atrazine by Advanced Oxidation Processes, Sixteenth International
Water Technology Conference (IWTC 16), Istanbul, Turkey. May.

Klavarioti M., Mantzavinos D. and Kassinos D. (2009), Removal of residual pharmaceuticals from aqueous systems by advanced oxidation processes, Environment International, 35, 402-417.

Kümmerer K., Al-Ahmad A., Mersch-Sundermann V. (2000), Biodegradability of some antibiotics, elimination of the genotoxicity and affection of wastewater bacteria in a simple test, Chemosphere, 40, 701-710.

Kunkel U. and Radke M. (2008), Biodegradation of acidic pharmaceuticals in bed sediments: insight from a laboratory experiment, Environmental Science \& Technology, 42, 72737279.

Langenhoff A., Inderfurth N., Veuskens T., Schraa G., Blokland M., Kujawa-Roeleveld K. and Rijnaarts H. (2013), Microbial Removal of the Pharmaceutical Compounds Ibuprofen and Diclofenac from Wastewater, BioMed Research International, 1-9.

Luo Y., Mao D., Rysz M., Zhou Q., Zhang H., Xu L. and J J Alvarez P. (2010), Trends in antibiotic resistance genes occurrence in the Haihe River, China, Environmental Science \& Technology, 44, 7220-7225.

McDowell D.C., Huber M.M., Wagner M., von Gunten U. and Ternes T.A. (2005), Ozonation of Carbamazepine in Drinking Water: Identification and Kinetic Study of Major Oxidation Products, Environmental Science \& Technology, 39, 80148022.

Méndez-Arriaga F., Torres-Palma R.A., Pétrier C., Esplugas S., Gimenez J. and Pulgarin C. (2008), Ultrasonic treatment of water contaminated with ibuprofen, Water Research, 42, 4243-4248.

Miranda-García N., Suárez S., Sánchez B., Coronado J.M., Malato S., and Maldonado M.I. (2011), Photocatalytic degradation of emerging contaminants in municipal wastewater treatment plant effluents using immobilized $\mathrm{TiO}_{2}$ in a solar pilot plant, Applied Catalysis B: Environmental, 103, 294-301.

Naddeo V., Belgiorno V., Kassinos D., Mantzavinos D., and Meric S. (2010), Ultrasonic degradation, mineralization and detoxification of diclofenac in water: Optimization of operating parameters, Ultrasonics Sonochemistry, 17, 179185.

Naddeo V., Belgiorno V., Ricco D.and Kassinos D. (2009a), Degradation of diclofenac during sonolysis, ozonation and their simultaneous application, Ultrasonics Sonochemistry, 16, 790-794.

Naddeo V., Meriç S., Kassinos D., Belgiorno V. and Guida M. (2009b), Fate of pharmaceuticals in contaminated urban wastewater effluent under ultrasonic irradiation, Water Research, 43, 4019-4027.

Naddeo V., Uyguner-Demirel C.S., Prado M., Cesaro A., Belgiorno V. and Ballesteros F. (2015), Enhanced ozonation of selected pharmaceutical compounds by sonolysis, Environmental Technology, 36, 1876-1883.

Nasuhoglu D., Yargeau V.and Berk D. (2011), Photo-removal of sulfamethoxazole $(\mathrm{SMX})$ by photolytic and photocatalytic processes in a batch reactor under UV-C radiation ( $\lambda$ max $=$ $254 \mathrm{~nm}$ ), Journal of Hazardous Materials, 186, 67-75.

Nicolle L.E. (2002), Urinary tract infection: traditional pharmacologic therapies, The American Journal of Medicine, 113, 35-44. 
Oller I., Malato S. and Sánchez-Pérez J.A. (2011), Combination of advanced oxidation processes and biological treatments for wastewater decontamination-a review, Science of the Total Environment, 409, 4141-4166.

Pandit A.B., Gogate P.R. and Mujumdar S. (2001), Ultrasonic degradation of 2: 4: 6 trichlorophenol in presence of $\mathrm{TiO}_{2}$ catalyst, Ultrasonics Sonochemistry, 8, 227-231.

Pérez-Estrada L.A., Maldonado M.I., Gernjak W., Agüera A., Fernández-Alba A.R., Ballesteros M.M. and Malato S. (2005), Decomposition of diclofenac by solar driven photocatalysis at pilot plant scale, Catalysis Today, 101, 219-226.

Rao Y.F., Chu W. and Wang Y.R. (2013), Photocatalytic oxidation of carbamazepine in triclinic-WO3 suspension: Role of alcohol and sulfate radicals in the degradation pathway, Applied Catalysis A: General, 468, 240-249.

Rizzo L., Meric S., Guida M., Kassinos D. and Belgiorno V. (2009), Heterogenous photocatalytic degradation kinetics and detoxification of an urban wastewater treatment plant effluent contaminated with pharmaceuticals, Water Research, 43, 4070-4078.

Rodríguez A., Rosal R., Perdigón-Melón J.A., Mezcua M., Agüera A., Hernando M.D., Letón P., Fernández-Alba A.R. and García-Calvo E. (2008), Ozone-Based Technologies in Water and Wastewater Treatment, in: The Handbook of Environmental Chemistry, Springer, Berlin, Heidelberg, Germany.

Secondes M.F.N., Naddeo V., Belgiorno V. and Ballesteros F. (2014), Removal of emerging contaminants by simultaneous application of membrane ultrafiltration, activated carbon adsorption, and ultrasound irradiation, Journal of Hazardous Materials, 264, 342-349.

Ternes T.A. (1998), Occurrence of drugs in German sewage treatment plants and rivers, Water Research, 32, 3245-3260.

Uyguner C.S., Suphandag S.A., Kerc A. and Bekbolet M. (2007), Evaluation of adsorption and coagulation characteristics of humic acids preceded by alternative advanced oxidation techniques, Desalination, 210, 183-193.

Wang Z., Srivastava V., Iftekhar S., Ambat I. and Sillanpää M. (2018), Fabrication of $\mathrm{Sb}_{2} \mathrm{O}_{3} / \mathrm{PbO}$ photocatalyst for the UV/PMS assisted degradation of carbamazepine from synthetic wastewater, Chemical Engineering Journal, 354, 663-671.

Xekoukoulotakis N.P., Drosou C.and Brebou C., Chatzisymeona E., Hapeshib E., Fatta-Kassinosb D. and Mantzavinos D. (2011), Kinetics of UV-A/TiO 2 photocatalytic degradation and mineralization of the antibiotic sulfamethoxazole in aqueous matrices, Catalysis Today, 161, 63-168. 